\title{
Covid-19 pandemic impact on maternal and child health services access in Nampula, Mozambique: a mixed methods research
}

Paulo Henrique das Neves Martins Pires ${ }^{1 *}$ (D), Cynthia Macaringue ${ }^{1}$, Ahmed Abdirazak1, Jaibo Rassul Mucufo ${ }^{1}$ Martins Abudo Mupueleque ${ }^{2}$, David Zakus ${ }^{3}$, Ronald Siemens ${ }^{4}$ and Celso Fernando Belo ${ }^{1}$

\begin{abstract}
Background: The Covid-19 pandemic has so far infected more than 30 million people in the world, having major impact on global health with collateral damage. In Mozambique, a public state of emergency was declared at the end of March 2020. This has limited people's movements and reduced public services, leading to a decrease in the number of people accessing health care facilities. An implementation research project, The Alert Community for a Prepared Hospital, has been promoting access to maternal and child health care, in Natikiri, Nampula, for the last four years. Nampula has the second highest incidence of Covid-19. The purpose of this study is to assess the impact of Covid-19 pandemic Government restrictions on access to maternal and child healthcare services. We compared health centres in Nampula city with healthcare centres in our research catchment area. We wanted to see if our previous research interventions have led to a more resilient response from the community.
\end{abstract}

Methods: Mixed-methods research, descriptive, cross-sectional, retrospective, using a review of patient visit documentation. We compared maternal and child health care unit statistical indicators from March-May 2019 to the same time-period in 2020. We tested for significant changes in access to maternal and child health services, using KrushKall Wallis, One-way Anova and mean and standard deviation tests.

We compared interviews with health professionals, traditional birth attendants and patients in the two areas. We gathered data from a comparable city health centre and the main city referral hospital. The Marrere health centre and Marrere General Hospital were the two Alert Community for a Prepared Hospital intervention sites.

Results: Comparing 2019 quantitative maternal health services access indicators with those from 2020, showed decreases in most important indicators: family planning visits and elective C-sections dropped 28\%; first antenatal visit occurring in the first trimester dropped 26\%; hospital deliveries dropped a statistically significant $4 \%$ ( $p=0.046)$, while home deliveries rose $74 \%$; children vaccinated down $20 \%$.

Conclusion: Our results demonstrated the negative collateral effects of Covid-19 pandemic Government restrictions, on access to maternal and child healthcare services, and highlighted the need to improve the health information system in Mozambique.

\footnotetext{
* Correspondence: druidatom@gmail.com

${ }^{1}$ Faculty oh Health Sciences, Lúrio University, Nampula, Mozambique

Full list of author information is available at the end of the article
} 
Keywords: Adolescent health, Children health, Covid-19, Health services access, Maternal health, Mozambique, Nampula

\section{Background}

Covid-19 virus pandemic has infected more than 30 million persons in the world (August 2020) [1], and continues to overload the national health care services in most countries [2]. Attempts to control the pandemic have had the secondary effect of limiting access to, and delivery of, public and private health care services [3], with severe unexpected collateral damage [4].

In Mozambique, the President declared the state of emergency at the end of March 2020, when there were no positive cases in the country. This limited travel, reduced all public services and gatherings. A national media information and education campaign, teaching preventive measures, was broadcast on television and radio across the country. These preventive measures might have reduced the number of infections: at the writing of this paper, Mozambique is 9th in the number of cases in Africa (3651). These have occurred mostly in men $(60 \%)$, mainly within the $25-44$-year-old age group (53\%); $58 \%$ of patients were asymptomatic, $34 \%$ had mild symptoms and there were 21 deaths $(0,6 \%$ death rate, the 7th smallest in Africa). Unfortunately, the preventive measures have led to diminished numbers of health care workers (HCWs) at primary care health centres and hospitals. The pandemic preventive measures aggravated by misinformation through social media networks [5], decreased the number of users at all health care levels. The effects on the national health programs are not well known but the negative impacts are documented in a British National Health System research paper, recommending HCWs and local authorities, pay close attention to prevent health care access restrictions [6].

Many women and children in Mozambique faced barriers as they tried to access health services, even before the COVID-19 pandemic began. Maternal and child health $(\mathrm{MCH})$ is one of the Mozambican government priorities. Interventions have included: implementing family planning (FP), ante-natal assistance, in-hospital deliveries, and childhood monitoring and vaccination programs. These target groups have high morbidity and mortality rates, far below the Sustainable Development Goals and now are at higher risk of worse outcomes given the national response to Covid-19 [7].

Over the last four years, the Alert Community for a Prepared Hospital implementation research (ACPH) project, a partnership between the Faculty of Health Science (FHS) of Lúrio University (UniLúrio) with the University of Saskatchewan (Canada) and Nampula Provincial Health Board (NPHB), has been promoting access to maternal, child and adolescent health care, at Marrere General Hospital (MGH) and Marrere Health Centre (MHC), in Natikiri, Nampula [8]. A base line study in 2016 helped to inform the design of seven strategies. These included interventions to inform local communities, leaders, and traditional birth attendants (TBAs), about sexual and reproductive health (SRH), and how to take an active role in improving their community health services. HCWs received training on emergency obstetrical care, new-born resuscitation, family centred care and obstetric ultrasound and MGH had a new operating room. A motorcycle ambulance system was developed to improve access for pregnant women [9].

Nampula is the third largest city in the country $(660,000$ people), and capital of the most populated province (6 million) in Mozambique. It has the third highest Covid-19 incidence in the country (517 cases), after Maputo and Cabo Delgado. The number of Covid19 cases is insignificant when compared to malaria, cholera, tuberculosis, human immunodeficiency virus (HIV) infections or road accidents deaths.

Given this, we planned to evaluate the impact of the state of emergency governmental preventative measures for Covid-19, and Ministry of Health (MH) priority decisions, on access to $\mathrm{MCH}$ care services, and the resilience of health care units (HUs) to the pandemic. We also want to access the effect of $\mathrm{ACPH}$ interventions in mitigating some of the secondary effects of Covid-19 preventive strategies in Natikiri, our intervention area, comparing with two representative care facilities in Nampula city.

\section{Methods}

We aimed to assess the access to maternal child healthcare units under the state of emergency due to Covid19. We used a mixed methods research, descriptive, cross-sectional, and retrospective, using a review of patient visit documentation. We compared maternal and child health care unit statistical indicators from MarchMay 2019 to the same time-period in 2020. This was then followed by interviews (the interview guide was developed for this study, see Appendices) of $\mathrm{MCH} \mathrm{HCWs}$, TBAs and clients using the system.

Quantitative data was obtained from health care monthly official statistics and the $\mathrm{MCH}$ statistics department in the HUs.

We gathered data from a comparative city health centre ( 25 de Setembro) and the main city referral hospital (Nampula Central). The MHC and MGH were the two ACPH intervention sites. 
Quantitative data was recorded on Microsoft Office Excel, double checked by research assistant and statistics professor, then analysed by number and percentage. SPSS21 software was used to test for significant changes in access to $\mathrm{MCH}$ services between 2019 and 2020, using KrushKall Wallis, One-way Anova and mean and standard deviation tests.

$\mathrm{ACPH}$ had a data base with phone numbers of TBAs in the Natikiri area. They were interviewed and in collaboration with them, we were able to find mothers and pregnant women willing to undergo an interview. HCWs were interviewed in their workplace. Subjects were a purposive sample of HCWs (nine), TBAs (six in Natikiri) and patients or users (six in Natikiri) of $\mathrm{MCH}$ services. Due to the Presidential declaration of a State of Emergency, in response to the COVID-19 pandemic, community members were interviewed by cell phone and HCWs in person respecting preventive measures. A total of 19 female participants were interviewed each for $30 \mathrm{~min}$ : six users (mothers and pregnant women), four TBAs from Natikiri district, three $\mathrm{MCH}$ nurses from $\mathrm{MHC}$, three $\mathrm{MCH}$ nurses from $\mathrm{HC} 25$ Setembro, and three from $\mathrm{NCH}$. The interviews were conducted in Portuguese or Emakhuwa (local language), following participant preference, by duly trained research assistants. The interviewers were fluent in the local language, were unknown to the participants, and took written notes. No interviews were repeated.

After receiving verbal consent interviews were recorded and subsequently transcribed to Microsoft Office Word by the same research assistants. Qualitative data was then transferred to NVIVO program for analysis. We used inductive content analysis, targeting four speech categories and nine themes: 1) Knowledge about Covid-19 disorder (cause, symptoms, prevention, social impact); 2) Impact of CoVid-19 on access to health care units (general population and individual client behaviour); 3) Health system response (HCWs MCH); 4) Impact on motorcycle-ambulance usage (demand, service).

This research was allowed by the FHS, NPHB, Nampula City Health Directorate, and approved by UniLúrio Bioethics Health Committee. We followed all Helsinki Declaration (2013) recommendations. All participants were volunteers, anonymity was guaranteed (no data was linked to identification), freedom to withdraw without any negative effect, and recording an informed consent. Recorded and transcript data were protected by a password to grant confidentiality. This research had no risk or remuneration to participants. They agreed to give their time and opinion on this topic to benefit the general population, contribute to improve public health policy interventions and implementation research.

\section{Results}

\section{Quantitative results}

Comparing the three months of Covid-19 pandemic in Natikiri, Mozambique in 2020, with the same period in 2019, concerning $\mathrm{MCH}$ services access indicators, data showed an increase in home deliveries (74\%), the number of pregnant women attending their first ante-natal visit (19\%), the number of women completing four ante-natal visits (19\%), and the number of well-baby visits (14\%). There were decreases in the number of women attending their first ante-natal visit at less than 12 weeks gestation (26\%), elective c-sections (28\%), all not statistically significant. There was a statistically significant decrease of $4 \%$ in hospital deliveries $(p=0,046$, see Table 1). In the non-intervention area, data showed an increase of $125 \%$ in the number of women with four antenatal visits, and a decrease of $12 \%$ of the number of women with first ante-natal visit in the first trimester, all not statistically significant (see Table 2).

Concerning children and adolescent health services access indicators, quantitative data in the ACPH intervention area showed a decrease in FP visits (28\%), number of childhood vaccinations (20\%) and children completely vaccinated (18\%), all without statistical significance (see Table 3). In non-intervention area we had a decrease of $16 \%$ in the number of children completely vaccinated and the number of adolescents and youth visits, all without statistical significance (see Table 4).

\section{Qualitative results \\ Knowledge of the disease}

When evaluating knowledge of the disease, we found that the basics were known by all groups. Users and TBAs were able to mention at least three major symptoms such as cough, fever and difficulty breathing.

"... it's a flu, in which the person has a cough, headache, neck pain, feels cold and has fever." (TBA, Natikiri).

They were also able to mention simple preventive methods, such as washing hands, social distancing, and wearing masks whenever in public.

$$
\begin{aligned}
& \text { "... we have to wash our hands with water and soap } \\
& \text { or ashes" (Post-partum women, Natikiri). } \\
& \text { "... we have to use masks, whenever we go out!" } \\
& \text { (Pregnant women, Natikiri). }
\end{aligned}
$$

As expected, HCWs had more knowledge on the origin of the disease,

"Covid-19 is a contagious disease originated in China and is caused by a new coronavirus SARSCoV-2" (MCH Nurse, MHC).

Also, on symptoms, and prevention methods: 
Table 1 Maternal health services in intervention area, Natikiri, 2019-2020

\begin{tabular}{|c|c|c|c|c|c|c|c|c|c|c|c|c|}
\hline \multicolumn{13}{|l|}{ MATERNAL HEALTH INTERVENTION AREA } \\
\hline MARRERE GENERAL HOSPITAL & 2019 & & & TOTAL & $\mathrm{M}+/-\mathrm{SD}$ & 2020 & & & TOTAL & $\mathrm{M}+/-\mathrm{SD}$ & & \\
\hline MARRERE HEALTH CENTRE & March & April & May & & & March & April & May & & & Change & $P$ \\
\hline Total 1st Ante-natal visits & 158 & NDA & 200 & 358 & $\begin{array}{l}165.33+/- \\
31.64\end{array}$ & 142 & 159 & 126 & 427 & $\begin{array}{l}142.33+/ \\
-16.50\end{array}$ & $19 \%$ & $0.327^{* *}$ \\
\hline $\begin{array}{l}\text { No. Women with Ante-natal Consult- } \\
\text { ation in } 1 \text { st trimester }\end{array}$ & 6 & 5 & 20 & 31 & $\begin{array}{l}10.33+/ \\
-8.38\end{array}$ & 7 & 6 & 10 & 23 & $\begin{array}{l}7.67+1 \\
-2.08\end{array}$ & $-26 \%$ & $0.658^{*}$ \\
\hline $\begin{array}{l}\text { No. women with } 4 \text { Ante-natal } \\
\text { Consultations }\end{array}$ & 48 & 45 & 85 & 178 & $\begin{array}{l}59.33+/- \\
22.28\end{array}$ & 36 & 123 & 52 & 211 & $\begin{array}{l}70.33+/ \\
-46.30\end{array}$ & $19 \%$ & $0.730^{* *}$ \\
\hline No. Post-partum Consultations & 153 & 155 & 185 & 493 & $\begin{array}{l}199.33+/ \\
-67.86\end{array}$ & 371 & 5 & 187 & 563 & $\begin{array}{l}108+/- \\
40.45\end{array}$ & $14 \%$ & $0.116^{* *}$ \\
\hline No. Intra- Hospital Deliveries & 135 & 111 & 142 & 388 & $\begin{array}{l}156.00+/ \\
-25.12\end{array}$ & 119 & 130 & 125 & 374 & $\begin{array}{l}126.67+/ \\
-5.51\end{array}$ & $-4 \%$ & $0.046^{*}$ \\
\hline No. Extra-hospital Deliveries & 4 & 7 & 8 & 19 & $\begin{array}{l}6.33+1 \\
-2.08\end{array}$ & 9 & 10 & 14 & 33 & $\begin{array}{l}11.00+/ \\
-2.66\end{array}$ & $74 \%$ & $0.074^{* *}$ \\
\hline No. Elective C-section & 8 & 3 & 7 & 18 & $\begin{array}{l}6.67+1 \\
-1.53\end{array}$ & 6 & 4 & 3 & 13 & $\begin{array}{l}4.33+/ \\
-1.53\end{array}$ & $-28 \%$ & $0.135^{*}$ \\
\hline Maternity - Emergency Room & 152 & 137 & 169 & 458 & $\begin{array}{l}152.67+/- \\
16.01\end{array}$ & 162 & 160 & 153 & 475 & $\begin{array}{l}158.33+/ \\
-4.72 p\end{array}$ & $4 \%$ & $0.588^{*}$ \\
\hline
\end{tabular}

NDA: data not available

Legend: ${ }^{*}$ Krus kal Wallis Test; ${ }^{* *}$ One-way ANOVA; M+/-SD - Mean +/- Standard deviation

When Krus kal Wallis and One-Way ANOVA tests are run, they showed that there was only statistical significance in number of intra-hospital deliveries between both time periods when $p$-value is 0.046 and $a=0.05$

"... if the person travels to a country contaminated by Covid-19 he has to be quarantined for 14 days" (MCH Nurse, 25 September HC).

"... everyone needs to use masks and maintain social distancing of $1.5 \mathrm{~m}$." (MCH Nurse, $\mathrm{NCH}$ ).
Impact of Covid-19 in access to health care units

During interviews, all groups stated that they anecdotally saw the number of people frequenting the HUs decreased significantly due to the fear of contamination in the HU.

The TBAs related that there was a reduction in the number of patients seen in the community. Also, both

Table 2 Maternal health services in non-intervention area, Nampula, 2019-2020

\begin{tabular}{|c|c|c|c|c|c|c|c|c|c|c|c|c|c|c|c|}
\hline \multicolumn{16}{|c|}{ MATERNAL HEALTH NON-INTERVENTION AREA } \\
\hline NAMPULA CENTRAL HOSPITAL & 2019 & & & & & & TOTAL & 2020 & & & & & & TOTAL & \\
\hline \multirow[t]{2}{*}{25 SEPTEMBER HEALTH CENTER } & $\mathrm{NCH}$ & $\begin{array}{l}25 \\
\mathrm{HC}\end{array}$ & $\mathrm{NCH}$ & $\begin{array}{l}25 \\
\mathrm{HC}\end{array}$ & $\mathrm{HCN}$ & $\begin{array}{l}25 \\
\mathrm{HC}\end{array}$ & & $\mathrm{NCH}$ & $\begin{array}{l}25 \\
\mathrm{HC}\end{array}$ & $\mathrm{NCH}$ & $\begin{array}{l}25 \\
\mathrm{HC}\end{array}$ & $\mathrm{NCH}$ & $\begin{array}{l}25 \\
\mathrm{HC}\end{array}$ & & \\
\hline & Mars & & April & & May & & & Mars & & April & & May & & & Change \\
\hline Total 1st Ante-natal visits & NDA & 1910 & 21 & 1640 & NDA & 1420 & 4991 & 86 & 1858 & 21 & 1597 & 35 & 1186 & 4783 & $-4 \%$ \\
\hline $\begin{array}{l}\text { No. Women with Pre-natal Consulta- } \\
\text { tion's 1st trimester }\end{array}$ & NDA & 2804 & NDA & 2640 & NDA & 2070 & 7514 & NDA & 2710 & NDA & 2025 & NDA & 1858 & 6593 & $-12 \%$ \\
\hline $\begin{array}{l}\text { No. women with } 4 \text { Ante-natal } \\
\text { Consultations }\end{array}$ & NDA & 203 & NDA & 180 & NDA & 247 & 630 & NDA & 197 & NDA & 236 & NDA & 982 & 1415 & $125 \%$ \\
\hline No. Post-partum Consultations & NDA & 947 & NDA & 815 & NDA & 1033 & 2795 & NDA & 836 & NDA & 1015 & NDA & 910 & 2761 & $-1 \%$ \\
\hline No. Intra- Hospital Deliveries & NDA & 735 & NDA & 852 & NDA & 855 & 2442 & 726 & 735 & 649 & 852 & 624 & 855 & 4441 & $\mathrm{NC}$ \\
\hline No. Extra- hospital Deliveries & NDA & NDA & NDA & NDA & NDA & NDA & 0 & NDA & NDA & NDA & NDA & NDA & NDA & 0 & NDA \\
\hline No. Elective C-section & NDA & NA & NDA & NA & NDA & NA & 0 & 302 & NA & 268 & NA & 301 & NA & 871 & NDA \\
\hline Maternity - ER & NDA & 410 & NDA & 390 & NDA & 413 & 1213 & 875 & 397 & 809 & 245 & 741 & 178 & 3245 & $\mathrm{NC}$ \\
\hline
\end{tabular}

NDA: data not available

NA: not applicable, service does not exist

NC: non comparable 
Table 3 Child and adolescent health services in intervention area, Natikiri, 2019-2020

\begin{tabular}{|c|c|c|c|c|c|c|c|c|c|c|c|c|}
\hline \multicolumn{13}{|c|}{ CHILD AND ADOLESCENT HEALTH INTERVENTION AREA } \\
\hline \multirow[t]{2}{*}{ MARRERE HEALTH CENTRE } & \multicolumn{3}{|c|}{2019} & \multirow[t]{2}{*}{ TOTAL } & \multirow[t]{2}{*}{$M+/-S D$} & \multicolumn{3}{|l|}{2020} & \multirow[t]{2}{*}{ TOTAL } & \multirow[t]{2}{*}{$\mathrm{M}+/-\mathrm{SD}$} & \multirow[b]{2}{*}{ Change } & \multirow[b]{2}{*}{ p } \\
\hline & March & April & May & & & March & April & May & & & & \\
\hline Family Planning Consultations & 175 & NDA & 276 & 451 & $\begin{array}{l}164.67+/ \\
-20.21\end{array}$ & 62 & 124 & 138 & 324 & $\begin{array}{l}187.67+/ \\
-18.3\end{array}$ & $-28 \%$ & $0.839^{* *}$ \\
\hline No. Children vaccinated & 156 & 236 & 202 & 594 & $\begin{array}{l}199.33+/ \\
-40.42\end{array}$ & 180 & 157 & 140 & 477 & $\begin{array}{l}159.00+/ \\
-20.08\end{array}$ & $-20 \%$ & $0.197^{* *}$ \\
\hline $\begin{array}{l}\text { No. children with complete } \\
\text { vaccination }\end{array}$ & 105 & 124 & 150 & 379 & $\begin{array}{l}126.33+/ \\
-22.59\end{array}$ & 172 & 68 & 69 & 309 & $\begin{array}{l}101.33+/ \\
-61.27\end{array}$ & $-18 \%$ & $0.544^{*}$ \\
\hline $\begin{array}{l}\text { Adolescents and Youth Friendly } \\
\text { Service visits }\end{array}$ & NDA & NDA & NDA & 0 & & NDA & NDA & NDA & 0 & & NDA & \\
\hline
\end{tabular}

NDA: data not available

Legend: " Kruskal Wallis Test; ${ }^{* *}$ One-way ANOVA; M+/-SD - Mean +/- Standard deviation

clients and TBAs, mentioned that due to the Covid19 pandemic, important tasks such as attending churches and mosques was prohibited. Initiation rites were also limited, as they are considered large gatherings. Work overall was affected, as people were forced to stay home. Farming was reduced to occasional days or ceased completely. Additionally, TBAs referred a lower number of their clients' visits. They mentioned that they also respected and enforced prevention measures, with the few community members who did visit them.

"The number of health professionals has decreased, and they leave early, so the waiting time has increased a bit" (TBA, Natikiri).

HCWs noted a much lower workload but also a reduction in $\mathrm{MCH}$ HCW's numbers and their work hours.

"The flux of patients is reduced; it may be because they fear coming to the hospital thinking that they might be contaminated here in the Nampula Central Hospital" (MHC Nurse, $\mathrm{NCH}$ ).
"... in the wards there is only one nurse per shift, and because of the pandemic if one gets sick, we will be forced to work every day to cover her!" $(\mathrm{MCH}$ Nurse, MGH).

Interviews with patients showed they recognised behaviour change in the population to prevent the infection, and this was resulting in a reduction in access to health services.

"... and I avoid going to the health centre, unless it is really urgent, because of this new infection!" (Postpartum woman, MHC).

\section{Health system response}

The lack of HCWs in HUs was seen in all four of centres assessed. This was a recurrent complaint from HCWs, TBAs and patients.

HCWs continue to educate the community regarding Covid-19 prevention methods, and about the necessary conditions for consultations.

"... community awareness speeches about prevention methods continue." (MCH Nurse, MHC).

Table 4 Child and adolescent health services in non-intervention area, Nampula, 2019-2020

\begin{tabular}{|c|c|c|c|c|c|c|c|c|c|c|c|c|c|c|c|}
\hline \multicolumn{16}{|c|}{ CHILD AND ADOLESCENT HEALTH NON-INTERVENTION AREA } \\
\hline NAMPULA CENTRAL HOSPITAL & 2019 & & & & & & TOTAL & 2029 & & & & & & TOTAL & \\
\hline \multirow[t]{2}{*}{25 SEPTEMBER HEALTH CENTER } & $\mathrm{NCH}$ & $\begin{array}{l}25 \\
\mathrm{HC}\end{array}$ & $\mathrm{NCH}$ & $\begin{array}{l}25 \\
\mathrm{HC}\end{array}$ & $\mathrm{NCH}$ & $\begin{array}{l}25 \\
\mathrm{HC}\end{array}$ & & $\mathrm{NCH}$ & $\begin{array}{l}25 \\
\mathrm{HC}\end{array}$ & $\mathrm{NCH}$ & $\begin{array}{l}25 \\
\mathrm{HC}\end{array}$ & $\mathrm{NCH}$ & $\begin{array}{l}25 \\
\mathrm{HC}\end{array}$ & & \\
\hline & \multicolumn{2}{|c|}{ March } & \multicolumn{2}{|l|}{ April } & \multicolumn{2}{|l|}{ May } & & \multicolumn{2}{|c|}{ March } & \multicolumn{2}{|l|}{ April } & \multicolumn{2}{|l|}{ May } & & Change \\
\hline Family Planning Consultations & NDA & 347 & 314 & 328 & NDA & 297 & 1286 & 401 & 315 & 314 & 293 & 234 & 389 & 1946 & NC \\
\hline No. Children vaccinated & NDA & 1593 & NDA & 1475 & NDA & 1497 & 4565 & 528 & 1567 & 494 & 1376 & 475 & 1538 & 5978 & NC \\
\hline $\begin{array}{l}\text { No. children with complete } \\
\text { vaccination }\end{array}$ & NA & 293 & NA & 190 & NA & 193 & 676 & NA & 219 & NA & 141 & NA & 209 & 569 & $-16 \%$ \\
\hline $\begin{array}{l}\text { Adolescents and Youth Friendly } \\
\text { Service visits }\end{array}$ & NA & 228 & NA & 251 & NA & 221 & 700 & NA & 189 & NA & 180 & NA & 218 & 587 & $-16 \%$ \\
\hline
\end{tabular}

NDA: data not available

NA: not applicable, service does not exist 
"... we reinforce measures and make the community understand to comply to the measures of prevention of this disease." (MCH Nurse, $\mathrm{NCH}$ ).

" ... the health professionals refuse to treat patients with no masks and that didn't wash their hands!" (MCH Nurse, $\mathrm{NCH}$ ).

Clients and TBAs mentioned that they continued to attend healthcare services, mostly to vaccinate their children. This was because the vaccines were no longer available in the communities through mobile brigades' services, forcing parents to go to the HU to get the child vaccinated.

"... these vaccines have not come to the community, so the mothers have to go to the hospital!" (Post-partum women, Natikiri).

\section{Impact on motorcycle-ambulance usage}

The motorcycle ambulance system was developed by the $\mathrm{ACPH}$ project as an urgent transport plan for pregnant women and other emergencies in the community. The users and TBAs mentioned that the motorcycle ambulances continued to circulate normally in some areas and in others reduced. The nurses in MHC and MGH were not able to provide information on this as they did not interact directly with the system.

"... the motorcycle ambulances have reduced their circulation because of the disease!" (TBA, Natikiri).

"... they are not using! Most of them have their own motorcycles." (Post-partum women, Natikiri).

When Kruskal Wallis and One-Way ANOVA test were run, they showed no statistical significance between both time periods because the $\mathrm{p}$-value $>\alpha>0.05$.

When Kruskal Wallis and One-Way ANOVA tests were run, they showed that there were no statistically significant differences between both time periods when $p$-value is $>0.5$.

When Kruskal Wallis and One-Way ANOVA test were run, they showed no statistical significance between both time periods because the $\mathrm{p}$-value $>\alpha>0.05$.

\section{Discussion}

Assessment of primary and secondary health care services during this pandemic, was done to determine level of universal health coverage. We assessed health care centres and hospitals, where primary care should be a strong indicator. Government's Covid-19 pandemic preventive measures might be reducing the number of Covid-19 cases in Mozambique, but they have reduced maternal, children and adolescent's health services access in Nampula. These facts are recognised globally [10]. It is also known that countries' primary health care systems strength, does not influence the pandemic mortality rate, which is more dependant of perceived stringent border control, movement restriction, and testing regimes [11].

The preventative measures promoted by the government targeting community health workers, TBAs, traditional leaders and healers through training [12], and the general population using a media campaign launched in May 2020, has led to a reduced access to the public health system, for regular primary and secondary health care services. This might be an opportunity for the $\mathrm{MH}$ to reformulate its population information and education strategy [13].

The health information system is deficient like in other countries in Africa [14], and this has limited our conclusions. The $\mathrm{NCH}$ has poor quality records and $\mathrm{MGH}$ does not incorporate all MHC indicators.

The number of pregnant women with four ante-natal visits increased, but we consider this result independent of Covid-19 impact, since the three previous visits have occurred before the state of emergency.

Comparing the city centre HUs with semi-rural Natikiri, with a higher rate of illiteracy, we saw a slight positive impact of $\mathrm{ACPH}$ project in maternal health (number of women in first ante natal visit, women with four antenatal visits, post-delivery visits, increasing faster than the demographic increase rate of 2.8\%) [15]. We did not see any difference in child health indicators (reduction in the number of children coming for vaccination and children completely vaccinated) and adolescent's health (Adolescent and Youth Friendly Service visits). Results support some ACPH outputs have led to a more informed community response. Our data suggests that Natikiri and Mozambican national public health education interventions, must improve their health care behaviours for children and adolescents, namely encouraging hospital deliveries, vaccination, and contraception [16]. Contraception is an essential need for adolescents and young adult patients, and new approaches should be developed to provide this crucial care [17].

Study limitations: Nampula province has had the highest incidence of Covid-19 positive cases in Mozambique in June 2020 (33\%, $293 / 889)$ [18], and this was one thing that motivated us to carry out this study. MH statistical data is not currently available in several HUs and there are several data collecting issues, limiting our analysis and conclusions. Telephone interviews due to emergency state' social distancing, led to loss of important communication indicators such as body language. Our study found a low impact of the Covid-19 pandemic governmental preventative measures on $\mathrm{MCH}$ care 
services access, probably since the assessed period included March (state of emergency declared on the 23rd), April and May, the early period of the pandemic.

\section{Conclusion}

Our results demonstrated negative collateral effects of Covid-19 pandemic governmental preventative measures on $\mathrm{MCH}$ care in Nampula, reducing the number of maternity deliveries and increasing home births.

$\mathrm{ACPH}$ project, informed the local population on SRH, moderately reducing some of these effects, but had no impact on child and adolescent health. This showed the need to improve the health information and education system in Mozambique, targeting preventive interventions with children and youth, namely on FP.

This could be done applying an HCWs training program about communication and values, and designing an innovative media campaign, reaching the rural population using local languages, and community health workers. $\mathrm{MH}$, although developing a media campaign to alert the population to access normal preventive services and chronic diseases consultations, is not reaching the general population, who have low Portuguese language capacity, and few radios and TVs. This will require investing in effective communication with urban and rural populations.

The ACPH project has implemented communitybased interventions to improve understanding of SRH, and further research will assess the long-lasting effect of this on reducing the negative collateral effects of Covid19 pandemic in Natikiri.

\section{Abbreviations}

ACPH: Alert Community for a Prepared Hospital; AYFS: Adolescent and Youth Friendly Service; Covid-19: SARS-CoV-2 virus infection; FHS: Faculty of Health Sciences; FP: Family planning; HCW: Health care worker; HIV: Human immunodeficiency virus; HU: Health unit; MCH: Maternal and child Health; MGH: Marrere general hospital; MH: Mozambican Ministry of Health; MHC: Marrere health centre; NCH: Nampula central hospital; NCHD: Nampula City Health Directorate; NPHB: Nampula Provincial Health Board; PHC: Primary health care; SRH: Sexual and reproductive health: TBA: Traditional birth attendant; UniLúrio: Lúrio University

\section{Supplementary Information}

The online version contains supplementary material available at https:/doi. org/10.1186/s12913-021-06878-3.

\section{Additional file 1}

\section{Acknowledgements}

Dr. António Falamique, Asimbawe Kiza and members of the Lúrio University Health Research Students Board.

\section{Consent to publish}

Not applicable.

\section{Authors' contributions}

All authors have read and approved the manuscript. PP: Study protocol conception and design, data analysis and interpretation, manuscript draft, final approval of the version to be published. CM: Study protocol design, data collection and interpretation, manuscript draft, final approval of the version to be published. AA: Study protocol design, data interpretation, manuscript draft, final approval of the version to be published. JM: Study protocol design, data interpretation, manuscript draft, final approval of the version to be published. MM: Study protocol design, data treatment, analysis and interpretation, final approval of the manuscript version to be published. DZ: Study protocol conception and design, data interpretation, manuscript draft, final approval of the manuscript version to be published. RS: Study protocol conception and design, data interpretation, manuscript draft, final approval of the version to be published. CB: Study protocol conception and design, data interpretation, manuscript draft, final approval of the version to be published.

\section{Authors' information}

PP, MD, Family Medicine Consultant, Faculty oh Health Sciences, Lúrio University, Nampula, Mozambique.

CM, MD, Faculty oh Health Sciences, Lúrio University, Nampula, Mozambique. AA, MD, Faculty oh Health Sciences, Lúrio University, Nampula, Mozambique. JM, Sociologist, Faculty oh Health Sciences, Lúrio University, Nampula, Mozambique.

MM, IT, Mussa Bin Bique University, Nampula, Mozambique.

DZ, Global Health Lecturer, Ryerson University, Toronto, Canada.

RS, MD Paediatrician PhD, Faculty of Medicine, University of Saskatchewan,

Saskatoon, Canada.

CB, MD, Faculty oh Health Sciences, Lúrio University, Nampula, Mozambique.

\section{Funding}

This study was not registered in any data base.

The study was funded by Lúrio University' Faculty of Health Sciences. The funding body had no role in the design of the study or collection, analysis, and interpretation of data, or in writing the manuscript.

\section{Availability of data and materials}

The authors declare that quantitative and qualitative data supporting the study findings are available when reasonable request is made to the corresponding author (druidatom@gmail.com).

\section{Declarations}

Ethics approval and consent to participate

This study was approved by the Lúrio University Bioethics Committee (02/ CBISUL/16) and authorised by the Nampula Provincial Health Directorate of the Mozambican Ministry of Health. All participants consented to participate, signing an informed consent form when directly interviewed, or verbally recorded on telephone interviews, due to Covid-19 state of emergency restrictions.

\section{Competing interests}

The authors declare they have no competing interests.

\section{Author details}

${ }^{1}$ Faculty on Health Sciences, Lúrio University, Nampula, Mozambique. ${ }^{2}$ University Mussa Bin Bique, Nampula, Mozambique. ${ }^{3}$ Ryerson University, Toronto, Canada. ${ }^{4}$ Faculty of Medicine, University of Saskatchewan, Saskatoon, Canada.

Received: 16 October 2020 Accepted: 3 August 2021

Published online: 23 August 2021

\section{References}

1. 360 GRN Revolution. Covid-19, Actualização. Worldometer. 28 Agosto 2020.

2. WHO. Pulse survey on continuity of essential health services during the Covid-19 pandemic. Interim report. World Health Organization. Geneva. 27 August 2020.

3. Melo RB, Tavares NT, Duarte R. Covid-19 and the invisible damage. Acta Med Port 2020 xxx;33(AOP):xxx-xxx • https://doi.org/10.20344/amp.13911.

4. Poudel A. A 200 percent increase in maternal mortality since the lockdown began. The Kathmandu May. 2020;27.

5. Kringos D, Carinci F, Barbazza E, Bos V, Gilmore K, Groene O, et al. Managing COVID-19 within and across health systems: why we need performance 
intelligence to coordinate a global response. Kringos et al Health Research Policy and Systems. 2020;18(1):80. https://doi.org/10.1186/s12961-020-00593-x.

6. Coronini-Cronberg S, Maile EJ, Majeed A. Health inequalities: The hidden cost of COVID-19 in NHS hospital trusts? Journal of the Royal Society of Medicine; 2020, Vol. 113(5) 179-184. doi: https://doi.org/10.1177/014107682 0925230.

7. Shepherd J, Friedland G. Preventing Covid-19 collateral damage. Downloaded from https://academic.oup.com/cid/advance-article-abstract/ doi/10.1093/cid/ciaa772/5858267 by guest on 18 June 2020 .

8. Belo C, Pires $P$, Josaphat J, et al. Maternal and new-born mortality: community opinions on why pregnant women and new-borns are dying in Natikiri, Mozambique. International Journal of Research, Volume 04 Issue 6 May 2017. p-ISSN: 2348-6848. e-IAAN: 2348-795x. http://edupediapublica tions.org/journals/

9. Pires P, Siemens R, Mupueleque M. Improving sexual and reproductive health and practice in Mozambican families with media campaign and volunteer family health champions. Fam Med Com Health 2019;7:e000089. doi: https://doi.org/10.1136/fmch-2018-000089, 4.

10. Roberton T, Carter ED, Chou VB, et al. Early estimates of the indirect effects of the COVID-19 pandemic on maternal and child mortality in low-income and middle-income countries: a modelling study. Lancet Glob Health 2020. Published Online May 12, 2020. https://doi.org/10.1016/. S2214109X(20)30229-1.

11. Goodyear-Smith F, Kinder K. Mannie C, et al. BJGP Open. 2020;4(4). https:// doi.org/10.3399/bjgpopen20X101129.

12. MISAU. Formação para Actores Comunitários sobre Covid-19. Ministério da Saúde. República de Moçambique. Maputo. 30 Abril 2020

13. Kennedy D. Support for school-aged-moms in Jamaica during Covid-19. Education Plus Development. Brookings. 2020.

14. Munkwa PA. Implications of Covid-19 on workplace: OSH context. AUDANEPAD. International Labour Organisation. 25 May 2020.

15. INE. Resultados Definitivos Censo 2017: IV Recenseamento Geral da População e Habitação. Instituto Nacional de Estatística. Maputo.2019. www. ine,gov.mz

16. Wilkinson TA, Kottke MJ, Berlan ED. Providing contraception for young people during a pandemic is essential Health care. JAMA Paediatrics Published online May 7,2020. Downloaded From: https://jamanetwork.com/ by Paulo Pires on 05/07/2020.

17. Wilkinson TA, Kottke MJ, Berlan ED. Providing Contraception for Young People During a Pandemic is Essential Health Care. JAMA Pediatr. September 2020 174(9):823-4. https:/doi.org/10.1001/jamapediatrics.2020.1884.

18. Direcção Nacional de Saúde Pública. Comunicado de imprensa de actualização da informação sobre a Covid-19 no país e no mundo. Ministério da Saúde. República de Moçambique. Maputo. 30 de Junho de 2020

\section{Publisher's Note}

Springer Nature remains neutral with regard to jurisdictional claims in published maps and institutional affiliations.

Ready to submit your research? Choose BMC and benefit from:

- fast, convenient online submission

- thorough peer review by experienced researchers in your field

- rapid publication on acceptance

- support for research data, including large and complex data types

- gold Open Access which fosters wider collaboration and increased citations

- maximum visibility for your research: over $100 \mathrm{M}$ website views per year

At BMC, research is always in progress.

Learn more biomedcentral.com/submissions 